\title{
Identification and Characterization of an Endoflagellar Antigen of Borrelia burgdorferi
}

\author{
James L. Coleman and Jorge L. Benach \\ The State of New York Department of Health, and Department of Pathology, The State University of New York \\ at Stony Brook, Stony Brook, New York 11794
}

\begin{abstract}
The 41-kD antigen of Borrelia burgdorferi is an immunodominant protein that is recognized early by antibodies in sera from Lyme disease patients and known to be associated with the endoflagella. We identified the 41-kD endoflagellar antigen to be a single polypeptide with an apparent isoelectric point (pI) of 6.5 by two-dimensional (2-D) electrophoresis. This polypeptide, which we designated P41F $\alpha$, was heavily labeled by ${ }^{125} I$ in 2-D autoradiographs of $B$. burgdorferi whole-cell lysates and was recognized by a murine monoclonal antibody (MCB1) and human antisera in 2-D immunoblots. $\mathrm{NH}_{2}$-terminal sequence analysis showed $80 \%$ homology between P41F $\alpha$ and the 33-kD endoflagellar protein of Treponema pallidum. Results of indirect immunofluorescence assays (IFA), Triton X-114 phase partitioning, and agglutination studies suggested a possible surface exposure of the polypeptide. Silver stained 2-D gels also revealed the presence of another 41-kD species, with an apparent pI of 6.6 (designated P41 $\beta$ ), which was not radioiodinated in 2-D autoradiographs, and was not recognized by MCB1 or human antisera. $\mathbf{N H}_{2}$-terminal sequence analysis of $\mathrm{P} 41 \beta$ revealed no homology with $\mathrm{P} 41 \mathrm{~F} \alpha$, leading to the conclusion that they are not related.
\end{abstract}

\section{Introduction}

Lyme disease is an increasingly recognized world-wide tickborne spirochetosis (1). While new clinical manifestations are being reported, Lyme disease as a multisystemic disorder involving the skin, the nervous system, the heart and the joints, was defined as we know it today by Steere and colleagues in 1977 (2).

Isolation of Borrelia burgdorferi from body fluids is difficult $(3,4)$, and visualization of the spirochetes in tissues is not a simple diagnostic task $(5,6)$. Thus, unlike other bacterial diseases that rely on the isolation and identification of the pathogen for diagnosis, the laboratory diagnosis of Lyme disease is through detection of antibodies to the spirochete.

Current serological procedures for the detection of antibodies in Lyme disease employ indirect immunofluorescence

Address reprint requests to Dr. Benach, State of New York Department of Health, Health Sciences Center, East Campus, State University of New York at Stony Brook, Stony Brook, NY 11794.

Received for publication 12 December 1988 and in revised form 7 March 1989.

J. Clin. Invest.

(c) The American Society for Clinical Investigation, Inc 0021-9738/89/07/0322/09 \$2.00

Volume 84 , July $1989,322-330$
(IFA) ${ }^{1}$ and the ELISA. Both procedures are insensitive in the early stages of the disease $(7,8)$, and questions remain regarding specificity, particularly as they pertain to cross-reactivity of sera from patients with other spirochetal diseases (7). Studies involving the sequential development of the antibody response to specific $B$. burgdorferi antigens have shown an early IgM response to a polypeptide with an approximate $M_{\mathrm{r}}$ of $41 \mathrm{kD}$. Antibodies of the IgG class are also initially directed to this polypeptide $(8,9)$. The antigen-specific response broadens markedly with advancing disease to include a multitude of Borrelial antigens. A recent study has shown that the early antibody response may recognize more antigens than was previously reported (10). However, the response to the $41-\mathrm{kD}$ antigen remains a predominant feature in the early and chronic phases of the disease. Three studies have utilized purified or enriched fractions of this polypeptide to improve on the early detection of antibodies (9-11).

Despite its marked immunogenicity, antibodies to the 41-kD polypeptide do not appear to have a protective role since patients with active, chronic Lyme disease show reactivity. Studies with monoclonal antibodies to this polypeptide traced the location of the antigenic determinant to the endoflagella of $B$. burgdorferi (12). The spirochetal endoflagella are located in the periplasmic space, between the protoplasmic cylinder and outer envelope (OE), and seemingly not accessible for antigenic recognition in an intact organism. Development of an initial antibody response to the endoflagella of $B$. burgdorferi could be explained in terms of the degradation of some of the invading organisms and to the subsequent selective antigenic presentation of a highly immunogenic endoflagellar polypeptide. Obviously, in order to cause subsequent and chronic disease, at least a portion of the organisms have to remain intact. Earlier studies have also shown that patients with other spirochetal diseases, and even some persons without disease have antibodies to this polypeptide (8), suggesting that some of the basis for cross-reactivity with other spirochetal diseases and even with other entities of bacterial origin could be traced to this molecule. Earlier attempts at characterization of the 41-kD polypeptide by silver stained two-dimensional (2-D) electrophoresis suggested the existence of a heterogeneous protein with a broad isoelectric point (pI) range. We now present evidence for the existence of two distinct polypeptides in the $41-\mathrm{kD}$ range, identifiable by $2-\mathrm{D}$ electrophoresis and $\mathrm{NH}_{2}$-terminal sequence, one of which is associated with the endoflagella of $B$. burgdorferi and responsible for the early antibody response. We also provide evidence to suggest a possible surface exposure of this polypeptide and evidence of

1. Abbreviations used in this paper: BCIP, 5-bromo-4-chloro-3-indoyl phosphate-toluidine salt; MCB1, monoclonal antibody MCB1; NBT, p-nitro-blue tetrazolium chloride; STEDTA, $10 \mathrm{mM}$ Tris, $1 \mathrm{mM}$ EDTA, pH 8.0; 2-D, two dimensional. 
$\mathrm{NH}_{2}$-terminal homology with endoflagellar proteins of other spirochetes.

\section{Methods}

Spirochetes. The Shelter Island, New York, isolate (1) of B. burgdorferi (B31) was used in all experiments. Cultures were grown in a previously described serum-free medium (13) at $33^{\circ} \mathrm{C}$.

Monoclonal antibody production. Monoclonal antibody MCB1 resulted from the fusion of BALB/c mouse splenocytes with P3X63Ag8.653 mouse myeloma cells. Immunization, fusion, and screening procedures have been described previously (14). Isotyping was done using an ELISA kit from Boehringer-Mannheim Biochemicals (Indianapolis, IN) according to the manufacturer's instructions.

$S D S-P A G E$ and immunoblotting. A Laemmli buffer system (15) using reagents of electrophoresis grade was used and has been described previously for $B$. burgdorferi $(9,14)$. Briefly, SDS-PAGE was carried out using $1.5-\mathrm{mm}$ thick gels containing $10 \%$ acrylamide, under reducing conditions. Transfer of spirochete proteins to nitrocellulose was carried out according to the method of Towbin et al. (16) and subsequent immunoblotting was also performed as described previously $(9,14)$, with some modifications. After incubation with either MCB1 supernatant (undiluted) or human antisera (1:100 in blocking solution $[9,14]$ ), the nitrocellulose was probed with either goat antimouse IgG or goat anti-human IgM conjugated to alkaline phosphatase (Organon Teknika, West Chester, PA). The substrate was prepared by adding $30 \mathrm{mg}$ of $p$-nitro blue tetrazolium chloride (NBT; Bio-Rad Laboratories, Richmond, CA) to $1 \mathrm{ml}$ of $70 \%$ dimethylformamide (DMF) and $15 \mathrm{mg}$ of 5-bromo-4-chloro-3-indoyl phosphate-toluidine salt (BCIP; Bio-Rad) to $1 \mathrm{ml}$ of $100 \%$ DMF with mixing. The two solutions were combined and then brought up to $100 \mathrm{ml}$ in $0.1 \mathrm{M}$ $\mathrm{NaHCO}_{3}, 1 \mathrm{mM} \mathrm{MgCl}$ (pH 9.8).

2-D electrophoresis. Whole spirochetes to be subjected to 2-D electrophoresis (17) were washed 3 times with PBS, pH 7.4 containing 5 $\mathrm{mM} \mathrm{MgCl} 2$ (PBS-Mg) and resuspended in sample buffer consisting of 9.5 M urea, 2\% NP-40 (Sigma Chemical Co., St. Louis, MO), 2\% ampholines (pH 3-10), (Pharmalyte; Pharmacia/LKB Biotechnology, Piscataway, NJ), and 5\% 2-mercaptoethanol. For the first dimension, $\sim 10-15 \mu \mathrm{g}$ was loaded onto isoelectric focusing (IEF) tube gels and separated electrophoretically in a Hoefer GT gel electrophoresis unit (Hoefer Scientific Instruments, San Francisco, CA). Ampholines with a pH range of 3 to 10 were used. pI were estimated by concurrently running a blank tube gel and slicing it into $0.5-\mathrm{mm}$ sections after IEF and extrusion. The slices were placed in $1 \mathrm{ml}$ of distilled water in individual test tubes and allowed to soak for $4 \mathrm{~h}$ with constant agitation before $\mathrm{pH}$ measurements were recorded. The second dimension consisted of SDS-PAGE as previously described. For some experiments, silver stains of SDS-PAGE as well as 2-D gels were done using a silver stain kit (Accurate Chemical and Scientific Corp., Westbury, NY).

Labeling of $B$. burgdorferi with ${ }^{125} I$. Spirochetes intended for radio-labeling were washed with $\mathrm{PBS}-\mathrm{Mg}$ to avoid competitive radioiodination of the BSA present in the medium, and $\sim 10^{9}$ cells were labeled with ${ }^{125}$ I by using Iodo-Beads (Pierce Chemical Co., Rockford, IL). The labeling was quenched by aspirating the suspension with a pipette tip previously rinsed with $1 \mathrm{M} \mathrm{KI}$. The labeled spirochetes were then washed five times with PBS-Mg in order to remove the unbound ${ }^{125}$ I. In all iodination experiments, spirochete counts were made (by darkfield microscopy) before and after labeling in order to assess the degree of cell lysis, if any, occurring as a result of the process.

Radioiodinated spirochetes were subjected to SDS-PAGE, then dried and autoradiographed using Kodak X-Omat AR film. 2-D electrophoresis autoradiography was performed as follows: proteins separated on 2-D gels were transferred electrophoretically to a nitrocellulose sheet which was then autoradiographed. The same nitrocellulose sheet was then probed with human serum or MCB1 thus making it possible to compare directly the autoradiograph and the blotted nitrocellulose.
Human sera. Serum specimens from our Lyme disease bank (stored at $-70^{\circ} \mathrm{C}$ ) were selected on the basis of their previously determined reactivity to the $41-\mathrm{kD}$ antigen of $B$. burgdorferi as determined by immunoblot. These sera had either IgM or IgG (or both) monotypic reactivity to this antigen only.

Purification of Endoflagella. Hardy's method involving the use of $\mathrm{CsCl}$ gradients (18), was used with modifications. 1-liter cultures of $B$. burgdorferi were washed three times with PBS-Mg and resuspended in $30 \mathrm{ml}$ of $2 \% N$-lauroylsarcosine, sodium salt (Sigma Chemical Co.) in $10 \mathrm{mM}$ Tris, $1 \mathrm{mM}$ EDTA, pH 8.0 (2\% STEDTA) and incubated at $37^{\circ} \mathrm{C}$ for $1 \mathrm{~h}$. Darkfield microscopy revealed spirochete structures of reduced thickness compared to controls, that were completely devoid of motility. The preparation was centrifuged at $48,000 \mathrm{~g}$ for $45 \mathrm{~min}$ at $25^{\circ} \mathrm{C}$ in a ultracentrifuge (model L5-75B; Beckman Instruments, Inc., Fullerton, CA) using a $75 \mathrm{Ti}$ fixed angle rotor. The pellet was resuspended in $30 \mathrm{ml}$ of $2 \%$ STEDTA, incubated at $37^{\circ} \mathrm{C}$ for $10 \mathrm{~min}$ and the centrifugation step was repeated. The pellet was resuspended in $30 \mathrm{ml}$ of $150 \mathrm{mM} \mathrm{NaCl}$ and sheared in a Waring blendor for a total of $10 \mathrm{~min}$ in a cold room with periodic interruptions in order to facilitate cooling. The preparation was then centrifuged at $150,000 \mathrm{~g}$ for $90 \mathrm{~min}$ at $15^{\circ} \mathrm{C}$ in the fixed angle rotor. The pellet was resuspended in $2 \mathrm{ml}$ of $2 \%$ STEDTA and loaded onto a $\mathrm{CsCl}$ step gradient consisting of 20,25,30, 35 , and $40 \% \mathrm{CsCl}$ steps in $0.2 \%$ STEDTA. The gradient was centrifuged overnight at $175,000 \mathrm{~g}$ in a Beckman SW40Ti swinging bucket rotor at $25^{\circ} \mathrm{C}$. The $\mathrm{CsCl}$ fractions were aspirated into separate tubes and an aliquot from each was analyzed by SDS-PAGE. Fractions containing single $41-\mathrm{kD}$ bands were pooled, diluted in an equal volume of $10 \mathrm{mM}$ Tris, $1 \mathrm{mM}$ EDTA, pH 8.0 and centrifuged at $175,000 \mathrm{~g}$ for $3 \mathrm{~h}$ at $25^{\circ} \mathrm{C}$ in the swinging bucket rotor. The pellet was then resuspended in and dialyzed extensively against distilled water.

IFA. Standard methods for the IFA were used. B. burgdorferi were freshly harvested from culture and washed twice in PBS-Mg. The pellet was smeared onto a glass microscope slide, air-dried, and fixed for 10 min in acetone. For tube assays, the spirochetes were washed twice in RPMI 1640 . The primary antibody was MCB1 culture supernatant (undiluted) or an irrelevant monoclonal antibody of similar Ig class and subclass, followed by goat anti-mouse IgG conjugated to FITC (Organon Teknika).

Electron microscopy. B. burgdorferi were harvested from culture and washed two times in PBS-Mg. After the final wash, the pellets were fixed in $3 \%$ glutaraldehyde in $0.2 \mathrm{M}$ cacodylate buffer, $\mathrm{pH} 7.4$, followed by $1 \%$ osmium tetroxide. The pellets were dehydrated in a graded ethanol series, embedded, sectioned, and stained with lead citrate and uranyl acetate.

Agglutination assays. B. burgdorferi from $50 \mathrm{ml}$ of culture were harvested and resuspended in medium without gelatin, Neopeptone, and CMRL-1066 (agglutination medium) (19). A constant number of spirochetes $\left(7 \times 10^{7}\right)$ was added in a volume of $100 \mu l$ to test tubes containing $100 \mu \mathrm{l}$ twofold serial dilutions of MCB1 culture supernatant in agglutination medium. Controls were also run in which spirochetes were added to twofold serial dilutions of an irrelevant monoclonal antibody of similar Ig class and subclass as MCB1 or fresh hybridoma medium (containing $10 \%$ equine serum) in agglutination medium. The dilutions were dispensed in $100 \mu$ l duplicates into 96 well, V-bottom microtiter plates (Linbro; Flow Laboratories, McLean VA) and incubated at $4^{\circ} \mathrm{C}$ for $2 \mathrm{~h}$. At the end of that period, the bottom of the plate was examined for signs of agglutination. Aliquots were also taken for examination by darkfield microscopy.

Triton $X-114$ phase partitioning. Triton X-114 (Sigma Chemical Co.) was prepared for use by dilution in PBS without $\mathrm{Ca}^{2+}$ and $\mathrm{Mg}^{2+}$ $(10 \% \mathrm{wt} / \mathrm{vol})$. It was allowed to go into solution at $4^{\circ} \mathrm{C}$. The solution was left overnight in a $37^{\circ} \mathrm{C}$ incubator and the following morning the liquid upper phase was discarded. Fresh PBS was added to initial volume. The process was repeated four times and the purified Triton $\mathrm{X}-114$ was stored at $4^{\circ} \mathrm{C}$ in a dark bottle.

Phase partitioning was done according to the method of Cunningham et al. (20). Freshly harvested $B$. burgdorferi were washed 


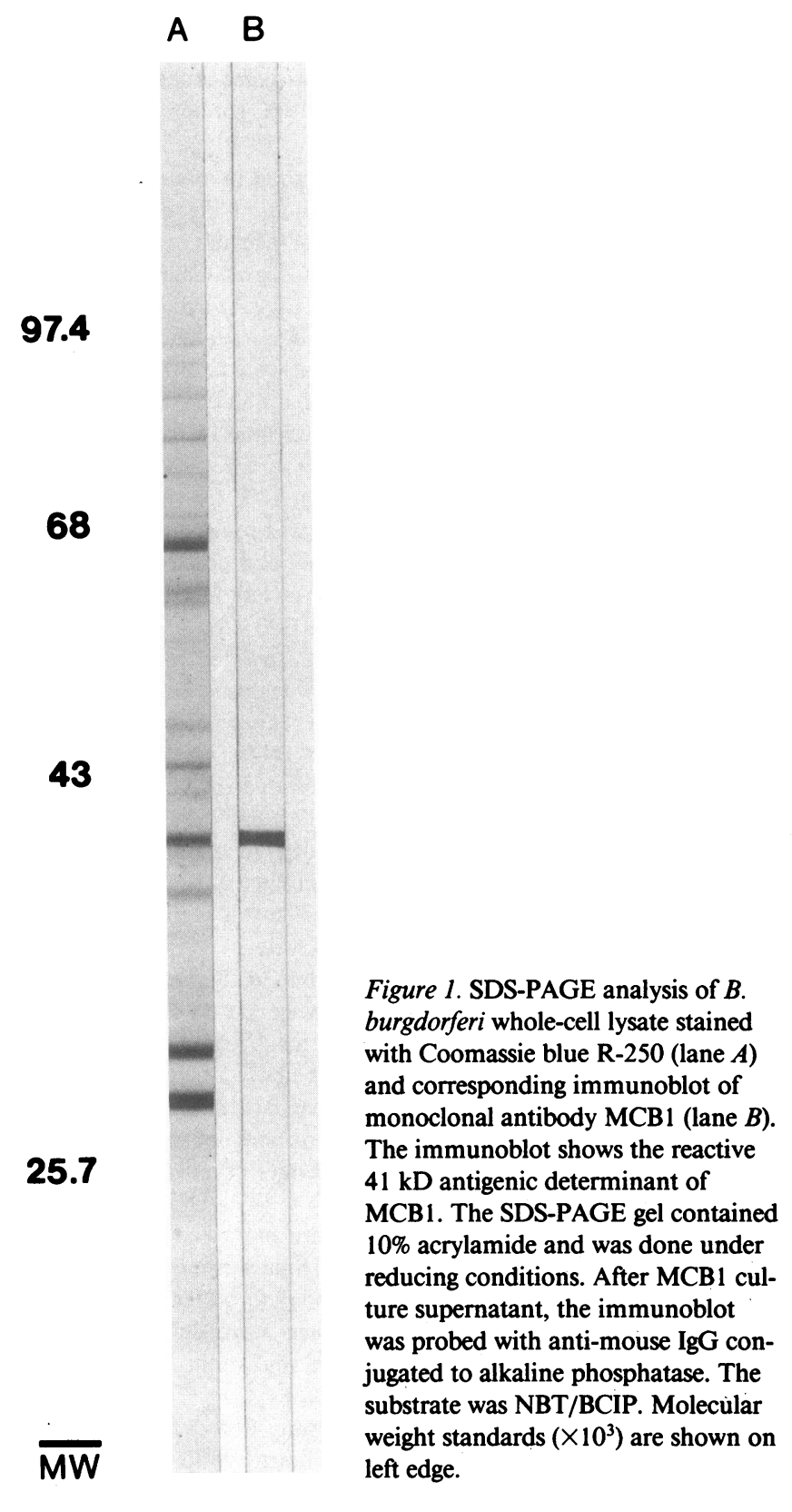

twice in PBS-Mg and the final pellet was resuspended in $5 \mathrm{ml}$ of $1 \%$ Triton X-114 in $50 \mathrm{mM}$ Tris, $50 \mathrm{mM}$ EDTA, pH 7.6 (Tris-EDTA). The solution was clarified by submerging in a $4^{\circ} \mathrm{C}$ ice bath for $15 \mathrm{~min}$ and then left at room temperature until the phases separated. The

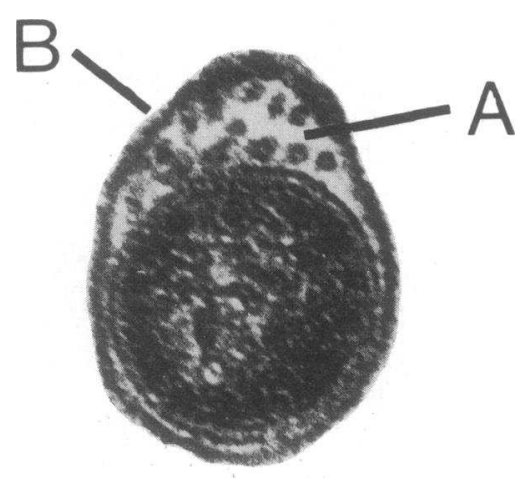

Figure 2. Transmission electron micrograph of $B$. burgdorferi in crosssection $(\times 200,000)$. The figure shows the endoflagella $(A)$ and the surrounding outer envelope $(B)$. The width of the cross-section is $\sim 0.25 \mu \mathrm{m}$.
97.4

68

43

25.7

$\overline{\mathrm{MW}}$

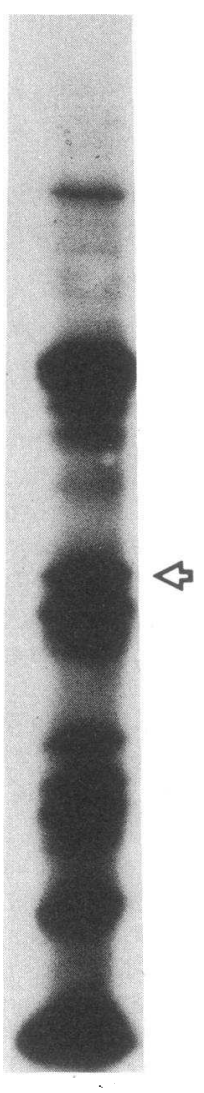

Figure 3. SDS-PAGE of ${ }^{125}$ I-labeled $B$. burgdorferi whole-cell lysate showing the 41-kD band (arrow). Electrophoresis running conditions as in Methods and Fig. 1. Kodak X-Omat AR film was exposed to the dried gel for $24 \mathrm{~h}$. Molecular weight standards $\left(\times 10^{3}\right)$ are shown on left edge.

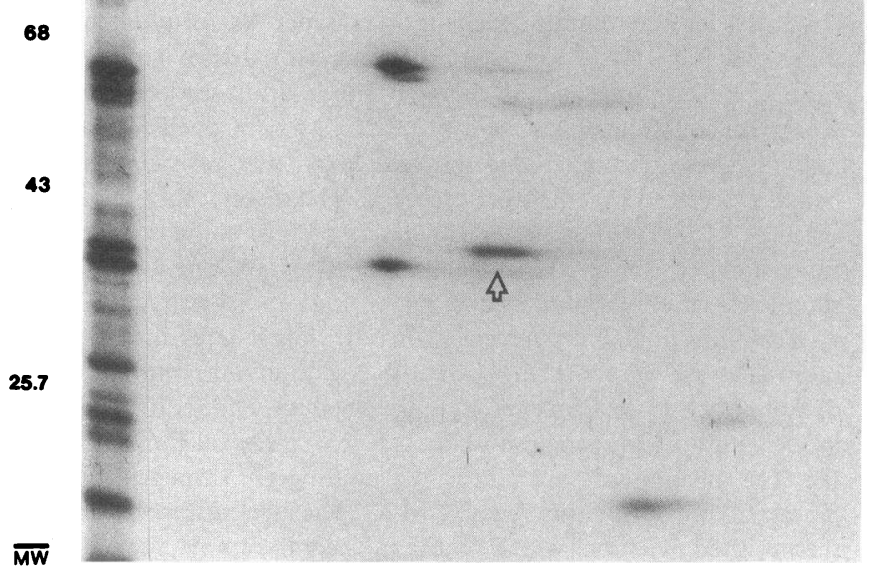

Figure 4. 2-D electrophoresis of ${ }^{125}$ I labeled $B$. burgdorferi whole-cell lysate showing 41-kD protein P41F $\alpha$ (arrow). Both first (IEF) and second dimension (SDS-PAGE) were done under reducing conditions. The first dimension used ampholytes with a pH range of 3 to 10. The second dimension SDS-PAGE gels contained $10 \%$ acrylamide. After electrophoresis, proteins on the 2-D gel were transferred to a nitrocellulose sheet and the sheet was autoradiographed as in Fig. 3. SDS-PAGE of $B$. burgdorferi ${ }^{125}$ I-labeled whole-cell lysate and molecular weight standards $\left(\times 10^{3}\right)$ are shown on left edge. The figure is oriented with the acidic end to the left and the basic end to the right. 


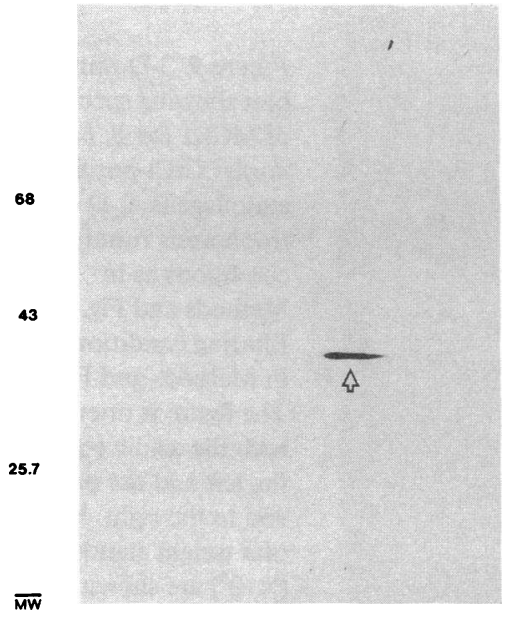

Figure 5. 2-D immunoblot analysis of the binding of monoclonal antibody MCB1 with 41-kD protein $\mathrm{P} 41 \mathrm{~F} \alpha$ (arrow) from B. burgdorferi whole-cell lysate. This is the same nitrocellulose sheet from Fig. 4 containing transferred ${ }^{125}$ I-labeled B. burgdorferi proteins which was probed with MCB1. Blotting conditions as in Methods and Fig. 1. The figure is oriented with the acidic end to the left and the basic end to the right. Molecular weight standards $\left(\times 10^{3}\right)$ are shown on the left edge.

upper (detergent soluble) phase was removed and the lower (detergent insoluble) phase was washed two times in Tris-EDTA. Both fractions were acetone precipitated (21) and resuspended in SDS-PAGE sample buffer.

$\mathrm{NH}_{2}$-terminal sequence analysis. 2-D electrophoresis was performed as described. The proteins were then transferred to polyvinylidene difluoride transfer medium (Immobilon; Millipore Corp., Bedford, MA), according to the method of Matsudiara (22), with modifications. After electrophoresis, the gels were soaked in transfer buffer $(25$ mM Tris, $192 \mathrm{mM}$ glycine in $20 \%$ methanol). An Immobilon membrane was briefly rinsed in $100 \%$ methanol and immediately immersed in transfer buffer. Transfer was done in a Bio-Rad Transblot tank overnight at $200 \mathrm{~mA}$. Following transfer the Immobilon membrane was washed for $5 \mathrm{~min}$ in distilled water, stained in $0.1 \%$ Coomassie Blue R-250 in 50\% methanol for $5 \mathrm{~min}$, and destained for $20 \mathrm{~min}$ in $50 \%$ methanol, $10 \%$ acetic acid. Stained $41-\mathrm{kD}$ spots were cut out of the Immobilon and stored at $-20^{\circ} \mathrm{C}$ until $\mathrm{NH}_{2}$-terminal sequencing. Sequencing was done using an Applied Biosystems 47A protein sequencer (Applied Biosystems, Foster City, CA) with an on-line Applied Biosystems 120A PTH analyzer. Standard programs were used.

\section{Results}

Monoclonal antibody MCB1. In immunoblots, MCB1 was shown to be directed to an antigenic determinant contained in the 41-kD band of $B$. burgdorferi whole-cell lysates (Fig. 1). Isotyping revealed $\mathrm{MCB} 1$ to be an $\mathrm{IgG}_{3}$ with kappa-light chains.

${ }^{125}$ I-labeling of $B$. burgdorferi. The endoflagella of $B$. burgdorferi are enclosed within the periplasmic space and surrounded by a protective outer envelope (OE) structure (Fig. 2). However, SDS-PAGE autoradiography of $B$. burgdorferi (after radioiodination by the Iodo-Beads method, a process that preferentially labels tyrosine residues of cell surface proteins) showed a prominent band of $M_{\mathrm{r}} 41 \mathrm{kD}$ (Fig. 3). A band of this molecular weight is known to represent the spirochetal endoflagella (12). Spirochete counts made before and after iodination failed to show any significant reduction in numbers after the iodination process, nor was there any obvious structural damage. In an attempt to identify this band we subjected ${ }^{125}$ Ilabeled spirochetes to 2-D electrophoresis and transferred the separated proteins to nitrocellulose. The nitrocellulose was
68

43

25.7

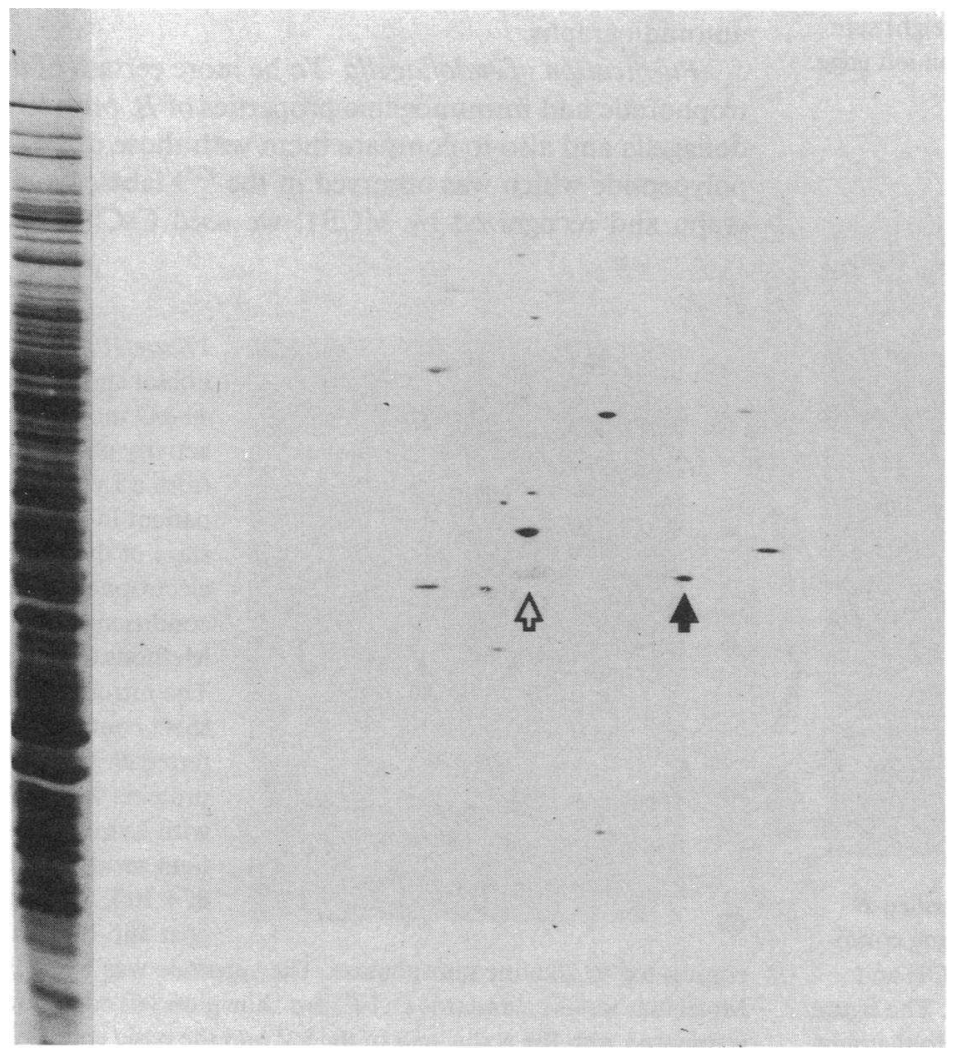

Figure 6. Silver stained 2-D electrophoresis gel of $B$. burgdorferi whole-cell lysate. The immunogenic $\mathrm{P} 41 \mathrm{~F} \alpha$ protein is shown by the clear arrow, and protein $\mathrm{P} 41 \beta$ is shown by the solid arrow. 2-D electrophoresis running conditions as in Methods and Fig. 4. Whole-cell lysate SDS-PAGE and molecular weight standards $\left(\times 10^{3}\right)$ are shown on left edge. The figure is oriented with the acidic end to the left and the basic end to the right. 


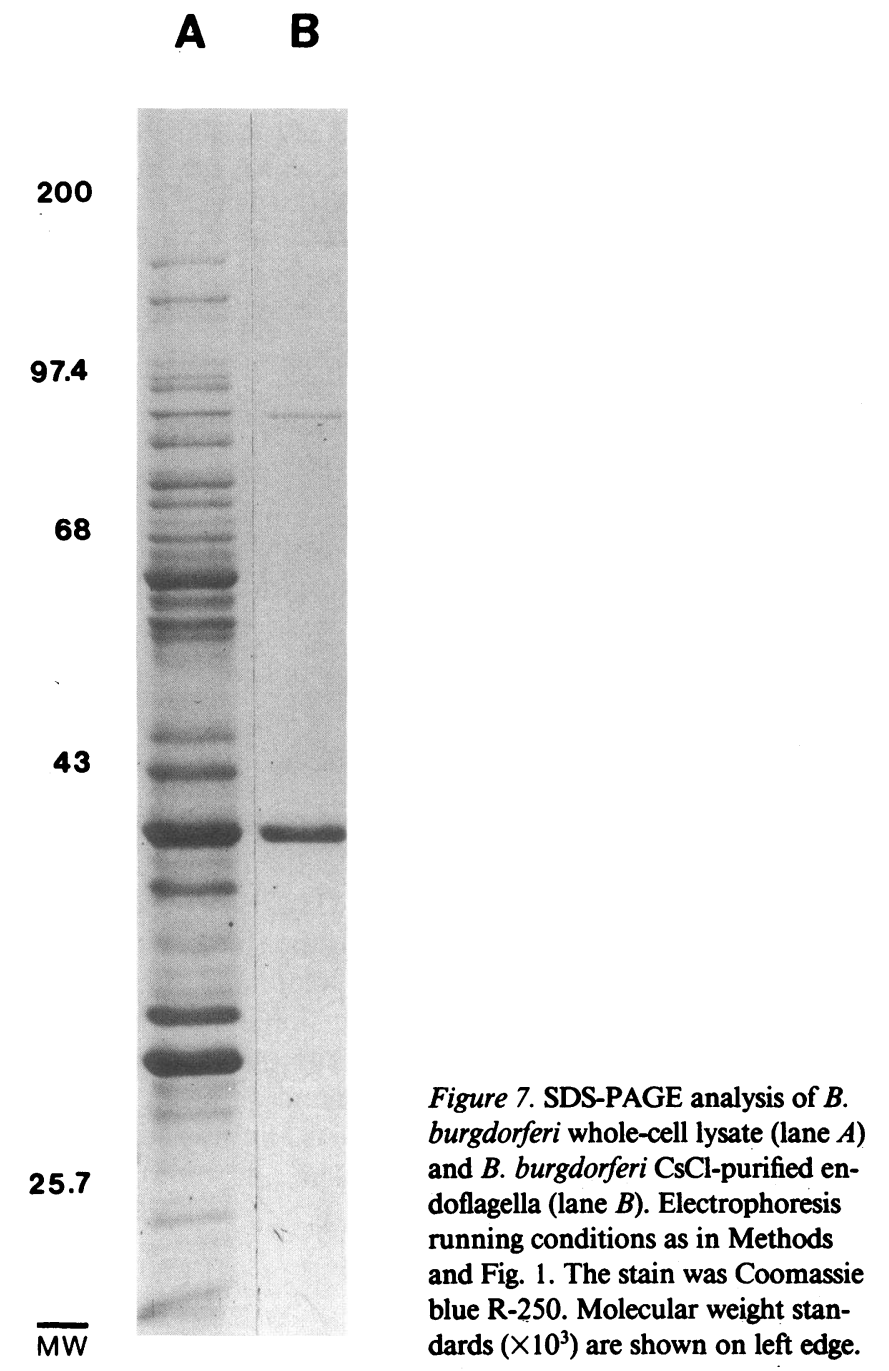

68

43

25.7

$\overline{M W}$
Figure 9. 2-D immunoblot showing specificity of MCB1 for B. burgdorferi $\mathrm{CsCl}$-purified endoflagella. 2-D electrophoresis running conditions as in Methods and Fig. 4. Blotting conditions as in Methods and Fig. 1. The figure is oriented with the acidic end to the left and the basic end to the right. Molecular weight standards $\left(\times 10^{3}\right)$ are shown on the left edge.

autoradiographed and this revealed only one $41-\mathrm{kD}$ polypeptide, with an apparent pI of 6.5 (Fig. 4). This protein was designated P41F $\alpha$. The same nitrocellulose sheet was probed with MCB1. The results showed that the point of reactivity of MCB1 and the polypeptide resolved in the ${ }^{125} \mathrm{I}$-labeled autoradiograph (P41F $\alpha$ ) were identical (Fig. 5).

Silver stained 2-D electrophoresis. 2-D electrophoresis of $B$. burgdorferi whole-cell lysates (Fig. 6), followed by silver staining, confirmed the presence of $\mathrm{P} 41 \mathrm{~F} \alpha$, but also revealed another protein (designated P41 1 ), with an apparent pI of 6.6. This protein drew our attention because it comigrated (in the molecular weight dimension) with $\mathrm{P} 41 \mathrm{~F} \alpha$, but was not immunogenic (was not recognized by Lyme disease patient sera or MCB1) and was conspicuously absent in ${ }^{125}$ I-labeled 2-D autoradiographs.

Purification of endoflagella. To be more certain of the electrophoretic and immunogenic properties of $B$. burgdorferi endoflagella and also to compare them with those of P41F $\alpha$, the polypeptide which was observed in the ${ }^{125}$ I-labeled autoradiograph and recognized by $\mathrm{MCB} 1$, we used $\mathrm{CsCl}$ gradients to

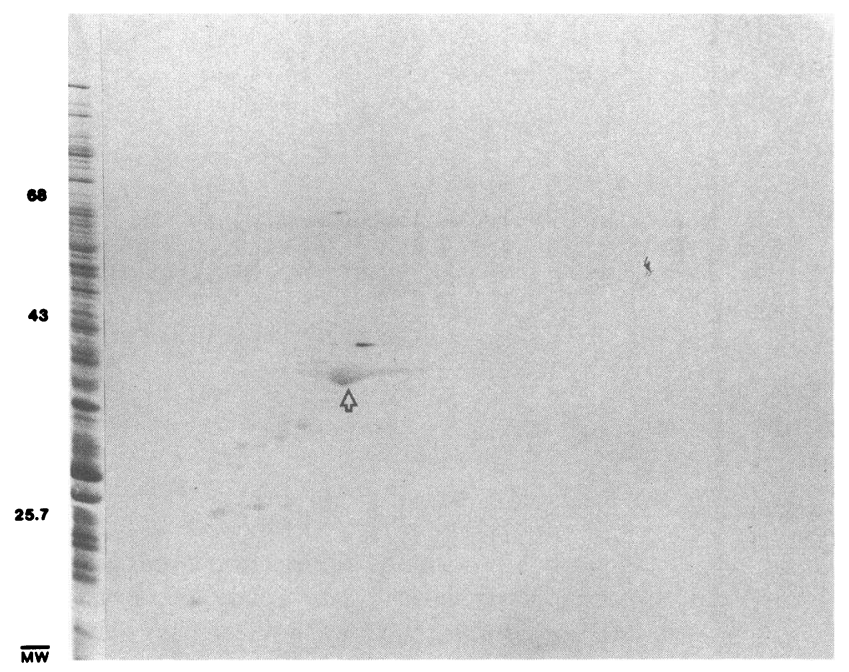

Figure 8. Silver stained 2-D electrophoresis gel of CsCl-purified $B$. burgdorferi endoflagella (arrow). 2-D electrophoresis running conditions as in Methods and Fig. 4. Whole-cell lysate SDS-PAGE and molecular weight standards $\left(\times 10^{3}\right)$ are shown on left edge. The figure is oriented with the acidic end to the left and the basic end to the right.

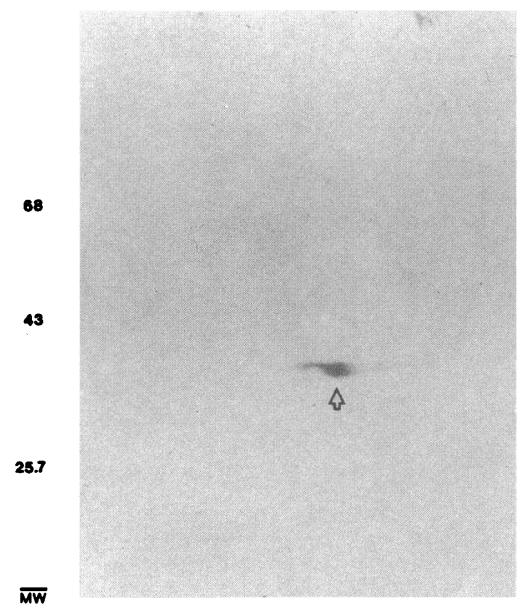

Figure 10. 2-D immunoblot showing the 41-kD monospecific reactivity pattern of sera from a Lyme disease patient in the early stage of the disease. 2-D electrophoresis running conditions as in Methods and Fig. 4. The nitro-cellulose sheet containing transferred $B$. burgdorferi proteins was probed with Lyme disease patient serum at a dilution of $1: 100$, followed by goat anti-human IgM conjugated to alkaline phosphatase. The substrate was NBT/BCIP. Molecular weight standards $\left(\times 10^{3}\right)$ are shown on left edge. The figure is oriented with the acidic end to the left and the basic end to the right. 


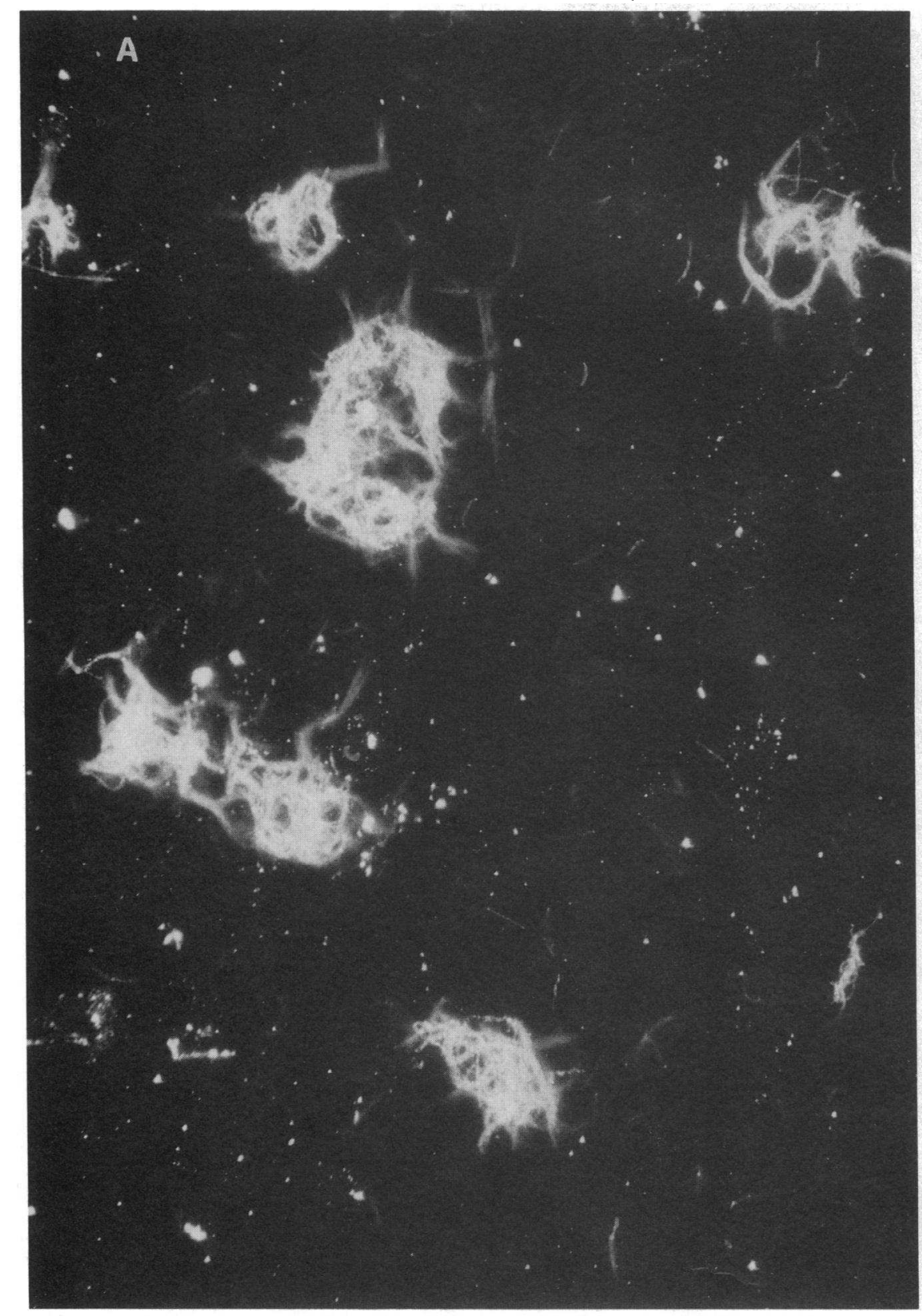

Figure 11. Agglutination assay in which $B$. burgdorferi were incubated at $4^{\circ} \mathrm{C}$ with MCB1 at a monoclonal dilution of 1:64 $(A)$. Agglutination assay control in which $B$. burgdorferi were incubated with an irrelevant monoclonal antibody $(B)$. purify these structures from other cellular elements. This procedure was developed to purify endoflagella from Treponema pallidum (18) and subsequently used to purify Borrelial endoflagella (12). SDS-PAGE analysis, followed by staining with Coomassie blue R-250 of the CsCl-purified B. burgdorferi endoflagella revealed a single band at $41 \mathrm{kD}$ which comigrated with the endoflagellar 41-kD band of the whole-cell lysate (Fig. 7). A possible 82-kD dimer was also observed. 2-D electrophoresis of the $\mathrm{CsCl}$-purified endoflagella was conducted, and following silver staining, this revealed a single $41-\mathrm{kD}$ species migrating in a similar fashion to $\mathrm{P} 41 \mathrm{~F} \alpha$, in addition to a number of lower molecular weight species (Fig. 8). MCB1 was also shown to be specifically directed toward antigenic determinants in the CsCl-purified endoflagella in 2-D immunoblots (Fig. 9).
2-D immunoblots using human antisera. 2-D immunoblots were performed in order to determine if Lyme disease patients (five patients) produce serum antibodies to $\mathrm{P} 41 \mathrm{~F} \alpha, \mathrm{P} 41 \beta$, and to $\mathrm{CsCl}$-purified endoflagella. Fig. 10 shows the results of a typical 2-D immunoblotting experiment using $B$. burgdorferi whole-cell lysate as antigen, with the reactivity being directed specifically toward P41F $\alpha$ only. These sera were also reactive toward the $\mathrm{CsCl}$-purified endoflagella in 2-D immunoblots and ELISAs (not shown).

Triton $X-114$ phase partitioning. Solubilization of $B$. burgdorferi $\mathrm{OE}$ by the nondenaturing detergent Triton X-114 has been utilized in the past to separate protoplasmic cylinders and associated endoflagella from surface components (20). In our experiments, although the endoflagellar $41-\mathrm{kD}$ band remained largely confined to the insoluble (nondetergent) phase there 


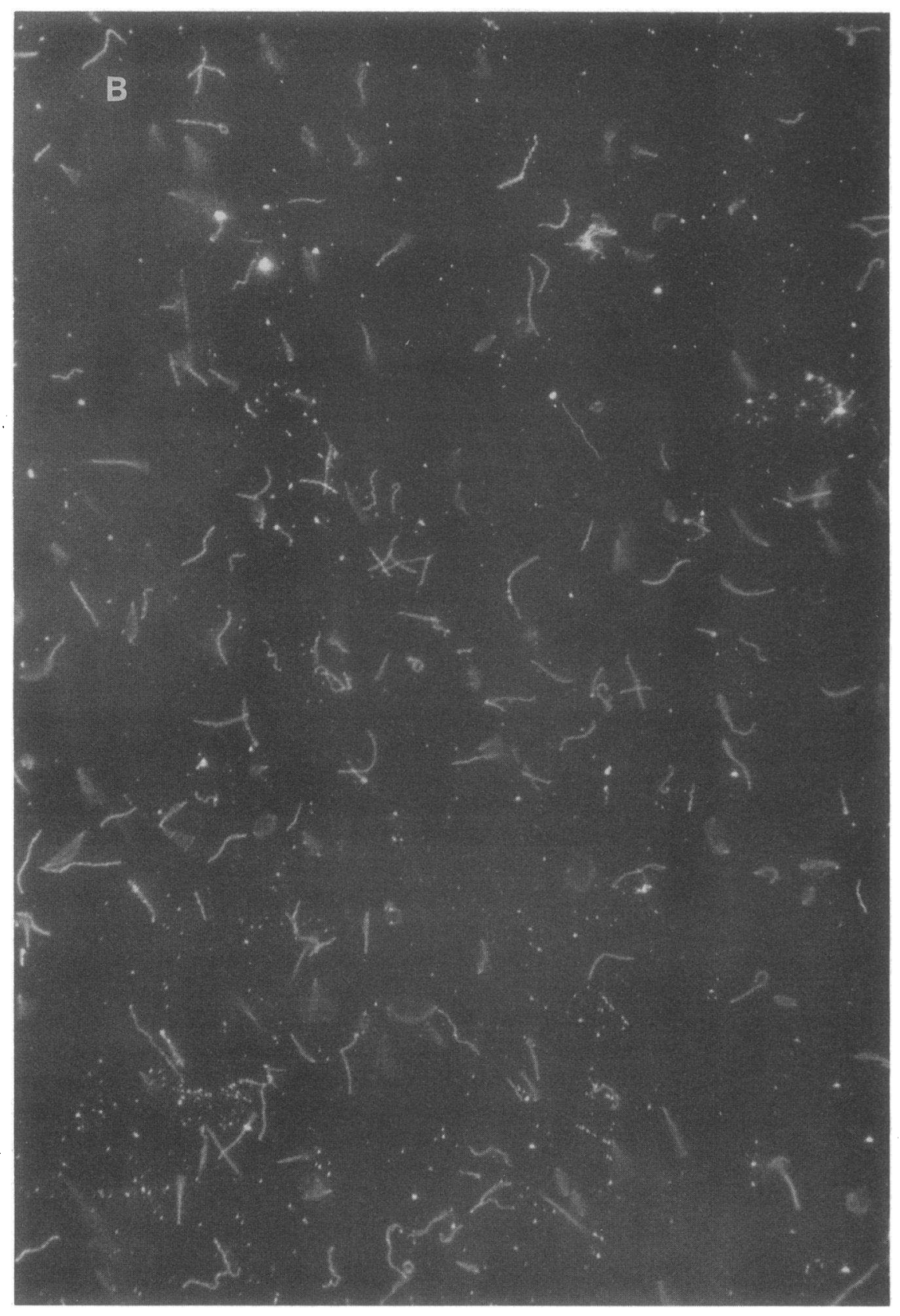

Figure 11 (Continued)

was also a minor amount that remained associated with the soluble (detergent) phase, indicating a possible association with spirochete surface components (not shown).

$I F A$. The reactivity of MCB1 was evaluated in IFA slide assays utilizing acetone-fixed $B$. burgdorferi and also in tube assays that used suspended spirochetes. In repeated experiments the $B$. burgdorferi fluoresced brightly in both the acetone-fixed and in the tube assays using suspended spirochetes, the latter result indicative of possible surface exposure of the epitope. Controls that used an irrelevant monoclonal antibody as the primary antibody were uniformly negative.

Agglutination assays. The presence of MCB1 caused $B$. burgdorferi cells to agglutinate up to a dilution of 1:512 but did not immobilize them. Fig. 11 shows the results of a typical agglutination assay. Controls in which spirochetes were incu- bated with an irrelevant monoclonal antibody or with hybridoma media alone but without MCB1 did not show agglutination.

$\mathrm{NH}_{2}$-terminal sequence analysis. We conducted studies on the $\mathrm{NH}_{2}$-terminal amino sequences of several $\boldsymbol{B}$. burgdorferi 41-kD proteins in order to understand their antigenic and structural character and to make comparisons with known $\mathrm{NH}_{2}$-terminal sequences from other pathogenic spirochetes. The $\mathrm{NH}_{2}$-terminal sequences of $(A) B$. burgdorferi whole-cell lysate 2-D electrophoresis separated $\mathrm{P} 41 \mathrm{~F} \alpha,(B) \mathrm{CsCl}$-purified 2-D electrophoresis separated $B$. burgdorferi endoflagella, $(C)$ $T$. pallidum $33-\mathrm{kD}$ endoflagellar antigen, and $(D) B$. burgdorferi whole-cell lysate 2-D electrophoresis separated P41 $\beta$ are presented in Fig. 12. Complete homology was noted between $B$. burgdorferi endoflagellar proteins $(A$ and $B)$. $T$. pallidum 33 
1

A. $\mathrm{H}_{2} \mathrm{~N}-$ KET - ILE - ILE - ASN - IIS - ASN - THR - SER - ALA - ILE

B. $\mathrm{H}_{2} \mathrm{~N}-$ IET - ILE - ILE - ASN - IIIS - ASN - THR - SER - ALA - ILE

C. $\mathrm{H}_{2} \mathrm{~N}-$ MET - ILE - ILE - ASN - EIS - ASN - MET - SER - ALA - MET

D. $\mathrm{H}_{2} N$ - SER - VAL - LEU - ASP - LEU - ILE - LYS - PRO - ? - VAL

Figure 12. $\mathrm{NH}_{2}$-terminal sequence analysis (10 residues) of: $(A) B$. burgdorferi whole-cell lysate $41 \mathrm{kD} \mathrm{P} 41 \mathrm{~F} \alpha,(B) B$. burgdorferi $\mathrm{CsCl}$ purified endoflagella, $(C) T$. pallidum major $(33 \mathrm{kD})$ endoflagellar antigen, and $(D) B$. burgdorferi whole-cell lysate $41 \mathrm{kD}$ P41 $\beta$; all after separation by 2-D electrophoresis. Boxes indicate areas of homology. The $\mathrm{NH}_{2}$-terminal sequence of $T$. pallidum appeared in: Blanco, D. R., et al. 1988. Antigenic and structural characterization of Treponema pallidum (Nichols strain) endoflagella. Infect. Immun. 56:168-175, with permission from the American Society for Microbiology.

kD endoflagellar antigen exhibited $80 \%$ homology with $(a)$ and (b). B. burgdorferi P41 $\beta$, however, showed no homology with any of the others.

\section{Discussion}

The earliest antibodies produced against $B$. burgdorferi by Lyme disease patients are of the IgM class and are directed against a polypeptide with an $M_{\mathrm{r}}$ of $41 \mathrm{kD}$. Later in the course of the illness, IgG antibodies are also formed against this antigen as well as a number of other cellular proteins of various molecular weights $(8-10)$. This polypeptide, which appears to be highly immunogenic, was subsequently identified as being a genus-specific (Borrelia) flagellin (12). However, it apparently has little or no protective value since patients who produce antibodies to this antigen go on to develop secondary and tertiary Lyme disease.

In this study, we have presented evidence that the endoflagellar antigen of $B$. burgdorferi migrates as a single polypeptide with an apparent pI of 6.5 in 2-D electrophoresis assays. We designated this protein P41F $\alpha$. This antigen is also heavily labeled when radioiodinated spirochetes are analyzed by SDSPAGE and 2-D electrophoresis. A murine monoclonal antibody generated in our laboratory, MCB1, was also shown to react specifically to the same antigen. In addition, 2-D immunoblots using sera from Lyme disease patients showed an identical monospecific pattern of reactivity. However, 2-D electrophoresis gels, when stained with silver or Coomassie blue R-250, also revealed the presence of another species (designated $\mathrm{P} 41 \beta$ ) which comigrated with $\mathrm{P} 41 \mathrm{~F} \alpha$ in the molecular weight dimension but was more basic, with an apparent pI of 6.6. This protein was not seen in $2-\mathrm{D}$ autoradiographs of ${ }^{125} \mathrm{I}$ labeled $B$. burgdorferi, was not recognized by Lyme disease patient sera in 2-D immunoblots, and was not present in silver stained 2-D gels of CsCl-purified endoflagella. In the last case, only one $41-\mathrm{kD}$ protein species was observed.

Previous evidence has suggested that the endoflagella of $B$. burgdorferi as well as those of other spirochetes are totally enclosed within the periplasmic space between the protoplasmic cylinder and the OE, and therefore not accessible to immune recognition in an intact organism. Production of $B$. burgdorferi endoflagellar antibodies early in the course of the disease suggests that the protective spirochetal $O E$ may be somehow damaged or compromised, thereby exposing the en- doflagella for antigenic recognition. Another explanation for such early endoflagellar recognition could be that the reactive antigenic determinant has a surface exposure. It is possible that the insertion points of the endoflagella at either end of the organism are not covered by the $\mathrm{OE}$. Alternatively, the antigenic determinant responsible for immune recognition may be shared by the two structures. Evidence has been provided to show that the endoflagellar subunits of $T$. pallidum can be borne on the outside of that organism $(23,24)$. In an attempt to investigate this we first labeled $B$. burgdorferi with ${ }^{125} \mathrm{I}$ in order to identify surface proteins. The $41-\mathrm{kD}$ protein seen in subsequent SDS-PAGE and 2-D electrophoresis autoradiographs was later identified, using MCB1, as the endoflagellar antigen. This procedure, however, labels tyrosine residues of cell surface proteins in a preferential, but not exclusive manner. Subsurface proteins can also be labeled if the OE is damaged in any way during the process. To further investigate, we produced a murine monoclonal antibody, MCB1, that is specific for a 41-kD endoflagellar epitope of $B$. burgdorferi for use as an immunological probe. IFA tube assays using suspended, nonfixed $B$. burgdorferi and MCB1, consistently exhibited positive reactions, a finding that suggests that the reactive epitope may be on the cell surface. However, the possibility exists and therefore must be considered, that these positive IFA reactions were due to disruption of the spirochetal OE occurring during the assay procedure.

Results of Triton X-114 phase partitioning experiments also suggested that the endoflagellar determinant may be located on the spirochete surface. In this case also, care must be taken in interpreting results due to the fact that the $41-\mathrm{kD}$ band seen in SDS-PAGE gels of the detergent-soluble phase may represent minor solubilization of otherwise internal flagellar proteins.

Monoclonal antibodies directed against surface antigens of cells in general and borreliae in particular (19) can cause agglutination when incubated with the appropriate target cells. In repeated experiments, MCB1 caused $B$. burgdorferi to agglutinate, but did not immobilize them. This was not surprising, in that spirochete immobilization is usually complement dependent and complement was not present during this assay. Even so, mouse $\mathrm{IgG}_{3}$ does not bind complement and therefore would not be expected to mediate immobilization.

Bacterial endoflagellar proteins have a distinctive amino acid composition which separates them from other proteins. Tryptophan and cysteine residues are absent (25-28). A rare exception is the case of Rhizobium meliloti (29) in which a single tryptophan residue was detected. In addition, neutral and acidic amino acids predominate and basic amino acids are lower in number (30). Sequence analysis identifying the $\mathrm{NH}_{2}$ terminus and a total of 10 amino acid residues of $B$. burgdorferi whole-cell lysate, 2-D electrophoresis separated P41F $\alpha$ and CsCl-purified 2-D electrophoresis separated endoflagella revealed complete and total homology between them, evidence that they are one and the same molecule and that only one major protein species is involved in the endoflagellar immune response. Also noted was the lack of cysteine and tryptophan in addition to the paucity of basic amino acid residues in these sequences. These findings are consistent with reports for a closely related spirochete, $T$. pallidum (23). The more basic P41 $\beta$ showed a total lack of homology by $\mathrm{NH}_{2}$-terminal sequence analysis. In view of this, and also due to its lack of 
reactivity in immunoblots, it must be regarded as being nonrelated.

Comparison of the $\mathrm{NH}_{2}$-terminal sequences (10 residues) of $B$. burgdorferi endoflagella (both whole-cell lysate P41F $\alpha$ and $\mathrm{CsCl}$-purified endoflagella) with that of the $33 \mathrm{kD}$ flagellar protein of $T$. pallidum (23) showed $80 \%$ homology, a trait that probably contributes to the basis of their cross-reactivity in serological assays $(7,31)$.

In conclusion, in this study we have shown that the endoflagellar protein of $B$. burgdorferi is a single, highly immunogenic polypeptide with an apparent pI of 6.5. It is consistent with other bacterial flagellins in its molecular properties and exhibits a 10 residue $\mathrm{NH}_{2}$-terminal amino acid sequence that is highly conserved with regard to a related pathogenic spirochete, $T$. pallidum. We have given preliminary evidence that in $B$. burgdorferi, the antigenic determinant for an endoflagellar-specific monoclonal antibody, and by extension, the human serological response, may be exposed, at least transiently, on the surface of the spirochete.

\section{Acknowledgments}

We would like to thank Dr. Gail S. Habicht, Dr. Howard B. Fleit, Dr. Marc G. Golightly, and Dr. Andrew Szczepanski for their critical review of this manuscript. The $\mathrm{NH}_{2}$-terminal sequences were performed at the Center for Analysis and Synthesis of Macromolecules of the State University of New York at Stony Brook.

Funding for this study was received from National Institutes of Health grants AI-23167 and AI-27044 to Dr. Benach.

\section{References}

1. Burgdorfer, W., A. G. Barbour, S. F. Hayes, J. L. Benach, E Grunwaldt, and J. P. Davis. 1982. Lyme disease-a tick borne spirochetosis? Science (Wash. DC). 216:1317-1319.

2. Steere, A. C., S. E. Malawista, J. A. Hardin, S. Ruddy, P. W. Askenase, and W. A. Andiman. 1977. Erythema chronicum migrans and Lyme arthritis. The enlarging clinical spectrum. Ann. Intern. Med. 86:685-698.

3. Benach, J. L., E. M. Bosler, J. P. Hanrahan, J. L. Coleman, G. S. Habicht, T. F. Bast, D. J. Cameron, J. L. Ziegler, A. G. Barbour, W. Burgdorfer, R. Edelman, and R. A. Kaslow. 1983. Spirochetes isolated from the blood of two patients with Lyme disease. N. Engl. J. Med. 308:740-742.

4. Steere, A. C., R. L. Grodzicki, A. N. Kornblatt, J. E. Craft, A. G. Barbour, W. Burgdorfer, G. P. Schmid, E. Johnson, and S. E. Malawista. 1983. The spirochetal etiology of Lyme disease. N. Engl. J. Med. 308:733-740.

5. Berger, B. W., M. H. Kaplan, I. R. Rothenberg, and A. G. Barbour. 1985. Isolation and characterization of the Lyme disease spirochete from the skin of patients with erythema chronicum migrans. J. Am. Acad. Dermatol. 13:444-449.

6. Duray, P. H., and A. C. Steere. 1988. Clinical pathologic correlations of Lyme disease by stage. Ann. NY Acad. Sci. 539:65-79.

7. Magnarelli, L. A., J. F. Anderson, and R. C. Johnson. 1987. Cross-reactivity in serological tests for Lyme disease and other spirochetal infections. J. Infect. Dis. 156:183-188.

8. Craft, J. E., D. K. Fischer, G. T. Shimamoto, and A. C. Steere. 1986. Antigens of Borrelia burgdorferi recognized during Lyme disease. J. Clin. Invest. 78:934-939.

9. Coleman, J. L., and J. L. Benach. 1987. Isolation of antigenic components from the Lyme disease spirochete: their role in early diagnosis. J. Infect. Dis. 155:756-765.

10. Grodzicki, R. L., and A. C. Steere. 1988. Comparison of im- munoblotting and indirect enzyme-linked immunosorbent assay using different antigen preparations for diagnosing early Lyme disease. $J$. Infect. Dis. 157:790-797.

11. Hansen, K., P. Hindersson, and N. Strandberg Pederson. 1988. Measurement of antibodies to Borrelia burgdorferi flagellum improves serodiagnosis in Lyme disease. J. Clin. Microbiol. 26:338-346.

12. Barbour, A. G., S. F. Hayes, R. A. Heiland, M. E. Schrumpf, and S. L. Tessier. 1986. A Borrelia-specific monoclonal antibody binds to a flagellar epitope. Infect. Immun. 52:549-554.

13. Benach, J. L., H. B. Fleit, G. S. Habicht, J. L. Coleman, E. M. Bosler, and B. P. Lane. 1984. Interaction of phagocytes with the Lyme disease spirochete: role of the Fc receptor. J. Infect. Dis. 150:497-507.

14. Benach, J. L., J. L. Coleman, and M. G. Golightly. 1988. A murine IgM monoclonal antibody binds an antigenic determinant in outer surface protein A, an immunodominant basic protein of the Lyme disease spirochete. J. Immunol. 140:265-272.

15. Laemmli, U. K., and M. Favre. 1973. Maturation of the head of bacteriophage T4. I. DNA Packing events. J. Mol. Biol. 80:575-599.

16. Towbin, H. T., T. Staehlin, and J. Gordon. 1979. Electrophoretic transfer of proteins from polyacrylamide gels to nitrocellulose sheets, procedure and some applications. Proc. Natl. Acad. Sci. USA. 76:4350-4354.

17. O'Farrell, P. H. 1975. High resolution two-dimensional electrophoresis of proteins. J. Biol. Chem. 250:4007-4021.

18. Hardy, P. H., Jr., W. R. Fredericks, and E. E. Nell. 1975. Isolation and antigenic characteristics of axial filaments from the Reiter treponeme. Infect. Immun. 11:380-386.

19. Barbour, A. G., S. L. Tessier, and S. F. Hayes. 1984. Variation in a major surface protein of Lyme disease spirochetes. Infect. Immun. 45:94-100.

20. Cunningham, T. M., D. D. Thomas, S. D. Thompson, J. N. Miller, and M. A. Lovett. 1988. Identification of Borrelia burgdorferi surface components by Triton X-114 phase partitioning. Ann. NY Acad. Sci. 539:376-378.

21. Hager, D. A., and R. R. Burgess. 1980. Elution of proteins from sodium dodecyl sulfate-polyacrylamide gels, removal of sodium dodecyl sulfate, and renaturation of enzymatic activity: results with sigma subunit of Escherichia coli RNA polymerase, wheat germ DNA topoisomerase, and other enzymes. Anal. Biochem. 109:76-86.

22. Matsudiara, P. 1987. Sequence from picomole quantities of proteins electroblotted onto polyvinylidene difluoride membranes. $J$. Biol. Chem. 262:10035-10038.

23. Blanco, D. R., C. I. Champion, J. N. Miller, and M. A. Lovett. 1988. Antigenic and structural characterization of Treponema pallidum (Nichols strain) endoflagella. Infect. Immun. 56:168-175.

24. Stam, L. V., R. L. Hodinka, P. B. Wyrick, and P. J. Bassford Jr. 1987. Changes in the cell surface properties of Treponema pallidum that occur during in vitro incubation of freshly extracted organisms. Infect. Immun. 55:2255-2261.

25. Bharier, M. A., and S. C. Rittenberg. 1971. Chemistry of axial filaments of Treponema zuelzerae. J. Bacteriol. 105:422-429.

26. Doetsch, R. N., and R. D. Sjoblad. 1980. Flagellar structure and function in eubacteria. Annu. Rev. Microbiol. 34:69-108.

27. Holt, S. C. 1978. Anatomy and chemistry of spirochetes. $M i$ crobiol. Rev. 42:114-160.

28. Joys, T. M. 1988. The flagellar filament protein. Can. J. Microbiol. 34:452-458.

29. Schleicher, L. R., and K. Bergman. 1986. The amino acid composition of Rhizobium meliloti flagellin: occurrence of a single tryptophan residue. Biochem. Biophys. Res. Commun. 100:16341641.

30. Kirschenbaum, D. M. 1975. A compilation of amino acid analyses of proteins. VII. Residues per molecule-5. Anal. Biochem. 66:123-150.

31. Baker-Zander, S. A., and S. A. Lukehart. 1984. Antigenic cross-reactivity between Treponema pallidum and other pathogenic members of the family Spirochaetaceae. Infect. Immun. 46:116-121. 